\title{
Lingual metastasis as an initial presentation of renal cell carcinoma
}

\section{Izumi Yoshitomi, ${ }^{1}$ Goro Kawasaki, ${ }^{1}$ Akio Mizuno, ${ }^{1}$ Masaharu Nishikido, ${ }^{2}$} Tomayoshi Hayashi, ${ }^{3}$ Shuichi Fujita, ${ }^{4}$ Tohru Ikeda ${ }^{4}$

${ }^{1}$ Department of Oral and Maxillofacial Surgery, Unit of Translational Medicine, Sciences, Course of Medical and Dental Sciences, Nagasaki University Graduate School of Biomedical Sciences, Nagasaki, Japan

${ }^{2}$ Department of Nephro-Urology, Unit of Translational Medicine, Sciences, Course of Medical and Dental Sciences, Nagasaki University Graduate School of Biomedical Sciences, Nagasaki, Japan

${ }^{3}$ Department of Pathology, Nagasaki University Hospital

${ }^{4}$ Department of Oral Pathology and Bone Metabolism, Unit of Basic Medical Sciences,Course of Medical and Dental Sciences, Nagasaki University Graduate School of Biomedical Sciences, Nagasaki, Japan

\footnotetext{
Abstract

Distant metastasis of malignant neoplasm to the oral soft tissue is extremely rare. We report a case of renal cell carcinoma (RCC) metastasizing to the tongue. A 47-year-old man visited our hospital with chief complaint of a lump on the middle third of the dorsum of his tongue, and the lesion fell off from the tongue. Although histopathological diagnosis of the mass was granuloma teleangiecaticum, similar nodule reappeared in the same area 2 weeks later. The second lesion was composed of granuloma teleangiectaticum and aggregation of neoplastic clear cells in ductal arrangement. The clear cells were immunohistochemically positive for EMA and CD10.
} 
The abdominal CT scan revealed a $5.5 \mathrm{~cm}$ mass in the left kidney, suggesting RCC. Thus the lingual lesion was consistent with metastaic RCC. There has been no recurrence for 2 years after the radical nephrectomy and local exicision of the tongue.

Keywords: Renal cell carcinoma, Lingual metastasis, CD10

\section{Introduction}

Renal cell carcinoma (RCC) is the third most frequent neoplasm to metastasize to the head and neck area, following breast and lung carcinomas[1]. The nose and paranasal sinuses are most commonly affected, followed by the oral cavity. RCC metastatic lesions to the tongue are extremely rare[2]. In the present study, we describe a case of renal cell carcinoma metastasis to the tongue, which was the first evidence of a primary tumor in the left kidney.

\section{Case presentation}

A 47-year-old male patient was referred to the Department of Oral and Maxillofacial Surgery, Nagasaki University Hospital, Nagasaki, Japan, because of a lump on the middle third of the dorsum of his tongue. The patient had been aware of the lump for approximately 2 months before visiting our hospital, and the lesion fell off from the tongue on the morning at the first visiting us. A clinical intraoral examination showed a reddish smooth lesion measuring approximately $5 \times 5 \mathrm{~mm}$ on the anterior dorsum of the tongue (Fig. 1). The lump that had fallen off was lightly red in color and was an elastic, soft, and smooth mass (Fig. 2). The patient had no history of malignant disease, drinking alcohol, or smoking. The clinical diagnosis included pyogenic granuloma and a benign tumor of the tongue. At the initial visit, the dropped lump was 
submitted for pathological examination. A microscopic examination revealed dilated blood vessels lined with plump endothelial cells and neutrophil infiltration under an ulcerated surface (Figs. 3). A diagnosis of granuloma teleangiectaticum was made. Two weeks later, a similar nodule reappeared on the same part of the tongue (Fig. 4). The histology of an excisional biopsy consisted of granuloma teleangiectaticum including aggregation of clear cells in the base of the polypoid protrusion. The round or cuboidal clear cells have mild atypical nuclei and scattered mitoses. Ductal formation and narrow stroma with rich blood vessles were also noticed (Fig. 5A and 5B). For the differential diagnosis between salivary malignant tumor and metastatic RCC, we performed immunohitochemical examination and ordered an MRI of the head and neck and a CT scan of the chest and abdomen. Immunohistochemically, the tumor cells were positive for CD10 as well as epithelial markers including EMA and cytokeratin AE1/AE3 (Fig. 5C and 5D). CD10 is regarded as good RCC marker to distinguish from other clear cell type carcinomas[3-5]. The abdominal CT scan revealed a $5.5 \mathrm{~cm}$ mass in the left kidney, suggesting RCC, and a mass in the right adrenal gland (Fig. 6). Furthermore, a chest CT scan revealed metastasis of the right adrenal gland, pleura, and bilateral multiple metastatic lesions in the lungs. Based on these findings, the lingual lesion was confirmed to be metastasis of RCC. The patient underwent laparoscopic left radical nephrectomy. At the same time, we performed an additional excision of the lingual lesion. The removed kidney contained yellowish-white nodular neoplasm reached the renal hilus accompanied with hemorrhage and necrosis (Fig. 7). Histologically, the neoplastic nodules were well demarcated and composed of tubular and trabecular patterns. Cystic lumens and delicate blood vessels were contained. The tumor cells have a rounded or polygonal shape, abundant clear cytoplasm and mildly atypical nuclei 
(Figs. 8). Although the kidney lesion was histopathologically diagnosed as clear cell renal cell carcinoma, there were no tumor cells in the tongue. The patient's surgical treatment was followed by interferon- $\alpha$, however the metastatic foci increased. Therefore, the patient was treated with targeted therapy by Sunitinib and by Sorafenib later. The patient was followed for 2 years after the radical nephrectomy and local exicision of the tongue, and had no evidence of recurrence in either the abdomen or tongue.

\section{Discussion}

Metastatic tumors to the tongue are extremely rare. Zegarelli et al. reported an incidence of $0.2 \%$ of 6,881 autopsy cases of various malignant diseases [2]. In addition, Friedlander reported that only $1 \%$ of all malignancies arising in the oral cavity are metastatic foci and of these, only 5\% appear on the tongue [6].

RCC represents $3 \%$ of all adult malignancies, and it is the third most frequent neoplasm to metastasize to the head and neck region, following breast and lung carcinoma [1]. Sgouras reported the most common sites of metastasis were the lung (76\%), regional lymph nodes (66\%), bone (42\%), and liver (41\%) [7]. Approximately $15 \%$ of all patients affected with RCC have metastasis in the head and neck region.have metastasis in the head and neck region, usually associated with lesions in other sites [8]. In the order of metastatic rate in the head and neck region, RCC affects the paranasal sinuses, larynx, jaws, temporal bone, thyroid gland, and parotid gland. However, metastatic RCCs to the tongue are extremely rare. 
We reviewed 29 cases of RCC metastasizing to tongue since 1973, including the present case (Table 1). In most cases, the lesions appeared after detection of the primary tumor, but 5 cases appeared as an initial presentation of RCC (Table 2).

Possible routes of the metastasis to the tongue include the systemic, venous, and lymphatic circulation [9]. Most metastasis are located on the base of the tongue, most likely due to its rich vascular supply (the dorsal lingual artery), or to the immobility of this area compared with other areas of the tongue [10]. RCCs invade the local vascular network of the kidney and spread through the systemic circulation. If there are no signs of pulmonary disease, metastatic spread can be explained through Batson's venous plexus or via the thoracic duct [11]. Batson's venous plexus extends from the skull to the sacrum. This valveless system offers little resistance to the spread of tumor emboli, especially during Valsalva maneuvers when there is an increase of intra-abdominal pressure, allowing the bypass of the pulmonary filters [12].

The treatment of RCC metastasizing to the oral cavity usually includes local excision to provide palliation of the symptom and to give patient comfort. A surgical excision has been performed to control pain and prevent bleeding and infection [13]. Marioni et al. indicated that radiotherapy is questionable as a primary treatment [14]. On the other hand, Azam et al. and Simo et al. have suggested the effectiveness of radiotherapy in the treatment of metastatic disease to achieve local control and for palliative management $[11,15]$. Chemotherapeutic agents such as vinblastine have been proved ineffective in the treatment of advanced $\mathrm{RCC}$, with a response rate lower than $10 \%$. Cytokine-based immunotherapy (interleukin- 2 and interferon- $\alpha$ ) were the only therapeutic option for advanced RCC patients several years ago. Shibayama et al. 
reported a complete response in a base of the tongue metastasis after interferon- $\alpha$ therapy [16]. However, the effect of this treatment is generally less than $20 \%[17]$. Recently target therapies are dramatically changing the landscape of advanced kidney cancer. Newer agents such as sunitinib and sorafenib, which are multiple tyrosine kinase inhibitors with proven antiangiogenic activity, have been approved for the treatment of RCCs. In the present case, the primary site was completely excised and the patient was administered adjuvant immunotherapy with interferon- $\alpha$. However the patient's treatment was changed to targeted therapy with sunitinib and sorafenib because of progressive disease. Will et al. reported that most patients die within 1 year after the detection of head and neck metastasis [18]. Campbell et al. reported the overall 5- and 10-year survival rates of patients with metastatic RCC are 5-30\% and 0-5\%, respectively[19]. Therefore, treatments that reduce morbidity and secure comfort are essential to improve the poor long-term prognoses.

\section{Acknowledgments}

We thank the staff of the Department of Radiology and Cancer Biology, Nagasaki University Graduate School of Biomedical Sciences.

\section{References}

1. Pritchyk, K.M., et al., Metastatic renal cell carcinoma to the head and neck. Laryngoscope, 2002. 112(9): p. 1598-602.

2. Zegarelli, D.J., et al., Metastatic tumor to the tongue. Report of twelve cases. Oral Surg Oral Med Oral Pathol, 1973. 35(2): p. 202-11.

3. $\quad$ Pires, F.R., et al., Metastatic renal cell carcinoma to the oral cavity and clear cell mucoepidermoid carcinoma: comparative clinicopathologic and immunohistochemical study. Oral Surg Oral Med Oral Pathol Oral Radiol Endod. 
109(4): p. e22-7.

4. Yamamoto, D., et al., Metastatic gastric tumor from renal cell carcinoma. Gastric Cancer, 2009. 12(3): p. 170-3.

5. Rivera, A.L., et al., Useful immunohistochemical markers in differentiating hemangioblastoma versus metastatic renal cell carcinoma. Neuropathology.

6. Friedlander, A.H. and R. Singer, Renal adenocarcinoma of the kidney with metastasis to the tongue. J Am Dent Assoc, 1978. 97(6): p. 989-91.

7. Sgouras, N.D., et al., An unusual presentation of a metastatic hypernephroma to the frontonasal region. Ann Plast Surg, 1995. 34(6): p. 653-6.

8. Gottlieb, M.D. and J.T. Roland, Jr., Paradoxical spread of renal cell carcinoma to the head and neck. Laryngoscope, 1998. 108(9): p. 1301-5.

9. Boles, R. and J. Cerny, Head and neck metastases from renal carcinomas. Mich Med, 1971. 70(16): p. 616-8.

10. Ol'shevskii, V.A., V.V. Fofanov, and T.N. Arifmetikova, [Metastasis of clear-cell cancer of the kidney to the tongueJ. Arkh Patol, 1984. 46(10): p. 85-6.

11. Azam, F., M. Abubakerr, and S. Gollins, Tongue metastasis as an initial presentation of renal cell carcinoma: a case report and literature review. J Med Case Reports, 2008. 2: p. 249.

12. Cheng, E.T., D. Greene, and R.J. Koch, Metastatic renal cell carcinoma to the nose. Otolaryngol Head Neck Surg, 2000. 122(3): p. 464.

13. Fukuda, M., et al., A case series of 9 tumors metastatic to the oral and maxillofacial region. J Oral Maxillofac Surg, 2002. 60(8): p. 942-4.

14. Marioni, G., et al., Uncommon metastatic site of renal adenocarcinoma: the oral tongue. Acta Otolaryngol, 2004. 124(2): p. 197-201.

15. Simo, R., et al., Metastatic renal cell carcinoma to the nose and paranasal sinuses. Head Neck, 2000. 22(7): p. 722-7.

16. Shibayama, T., et al., Disappearance of metastatic renal cell carcinoma to the base of the tongue after systemic administration of interferon-alpha. Eur Urol, 1993. 24(2): p. 297-9.

17. Basso, M., A. Cassano, and C. Barone, A survey of therapy for advanced renal cell carcinoma. Urol Oncol. 28(2): p. 121-33.

18. Will, T.A., N. Agarwal, and G.J. Petruzzelli, Oral cavity metastasis of renal cell carcinoma: A case report. J Med Case Reports, 2008. 2: p. 313.

19. Campbell SC, Novick AC, Bukowski RM, Renal tumors. In Campbell-Walsh Urology. Volume 2. 9th edition. Edited by: Wein AJ. Philadelphia, PA: Saunders Elsevier; 2007:1582-1632. 
20. Satomi Y, et al. Three cases of hypernephroma metastasis in the otorhinopharyngolaryngeal region (parotid gland, nasal cavity, tongue and gingiva). Jpn J Clin Urol 1974;28(8):611-616.

21. Fitzgerald RH et al. Renal cell carcinoma involving oral soft tissues. J Oral Maxillofac Surg 1982;40(9):604-606.

22. Kitao $\mathrm{K}$ et al. Metastatic Gravitz tumor of the base of tongue. A case report. Jibi Inkoka, 1986;58(1): 67-70.

23. Inai $\mathrm{T}$ et al. A renal cell carcinoma with metastatis to the tongue. Acta Urol Jpn 1987;33(8): 1240-1243.

24. Matsumoto A, Iio S Metastasis of renal cell carcinoma to the tongue: A case report. Nishinihon J Urol 1987;49:1147-1149.

25. Kapoor VK et al. Renal cell carcinoma metastatic to the tongue. J Indian Med Assoc 1987;85(4):119-120.

26. Madison JF et al. Pathologic quiz case 2. Arch Otolaryngol Head Neck Surg 1988;114(5):570-573.

27. Ishikawa $\mathrm{J}$ et al. Renal cell carcinoma metastatic to the tongue: a case report. Acta Urol Jpn 1991;37(3):263-265.

28. Okabe Y et al. View from beneath: pathology in focus. Renal cell carcinoma metastasis to the tongue. J Laryngol Otol 1992;106(3);282-284.

29. Ziyada W F et al. Expectorated tissue leading to diagnosis of renal

adenocarcinoma. J Laryngol Otol 1994;108(12):1108-1110.

30. Airoldi $\mathrm{M}$ et al. Head and neck metastases of renal cancer after nephrectomy: a report of 2 cases. Tumori 1996;81(3) :213-214.

31. Aguirre A. Rinaggio J Lingual metastasis of renal cell carcinoma. J Oral Maxillofac Surg 1996;54(3):344-346.

32. Konya E. et al. Two cases of renal cell carcinoma detected by metastasis to another organ. Hinyokika Kiyo 1997;43(9): 647-650.

33. Tomita T. et al. Palliative radiotherapy for lingual metastasis of renal cell carcinoma. Auris Nasus Larynx 1998;25(2):209-214.

34. Navarro F. et al. Metastatic renal cell carcinoma to the head and neck area. Tumori. 2000;86(1):88-90.

35. Goel M C. et al. Lingual metastasis from renal cell carcinoma management and review of the literature. Urol Int 2003;71(4):418-421.

36. Lang EE. A case of renal cell carcinoma metastatic to the nose and tongue. Ear Nose Throat J. 2003 May;82(5):382-3.

37. Kyan A et al. Renal cell carcinoma to the base of tongue: a case report. 
Hinyokika Kiyo 2004;50(11):791-793.

38. Tachi T. et al. Renal cell carcinoma with metastasis to the tongue. Pract. otol. (Kyoto)2005;98(7):543-546.

39. Torres-Carranza E et al. Airway obstruction due to metastatic renal cell carcinoma to the tongue. Oral Surg Oral Med Oral Pathol Oral Radiol Endod 2006;101(3):E76-78.

40. Cochrane T J. Renal cell carcinoma: A rare metastasis to the tongue--a case report. Dent Update 2006;33(3):186-187.

41. Tanaka Y. et al. A case of renal carcinoma metastatic to the tongue. Pract. otol. (Kyoto)2007;100(5):375-378.

42. Basely M. et al. A rare presentation of metastatic renal clear cell carcinoma to the tongue seen on FDG PET. Clin Nucl Med 2009;34(9):566-569. 
Fig.1

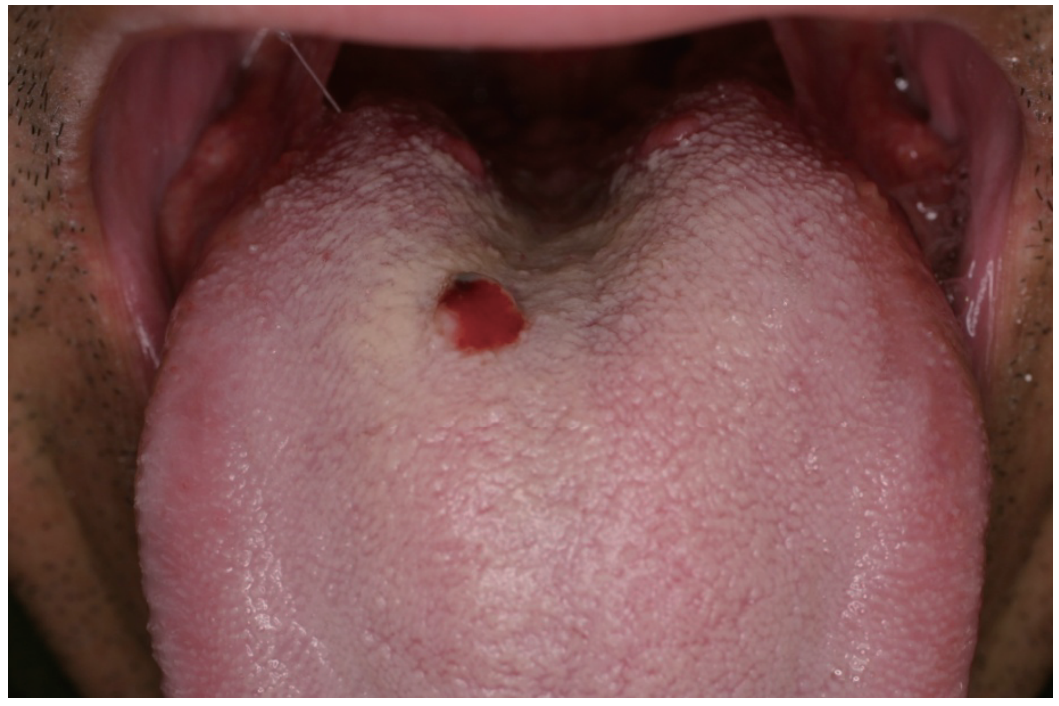

Fig.1 Clinical appearance of the lingual lesion at the time of initial examination 
Fig.2

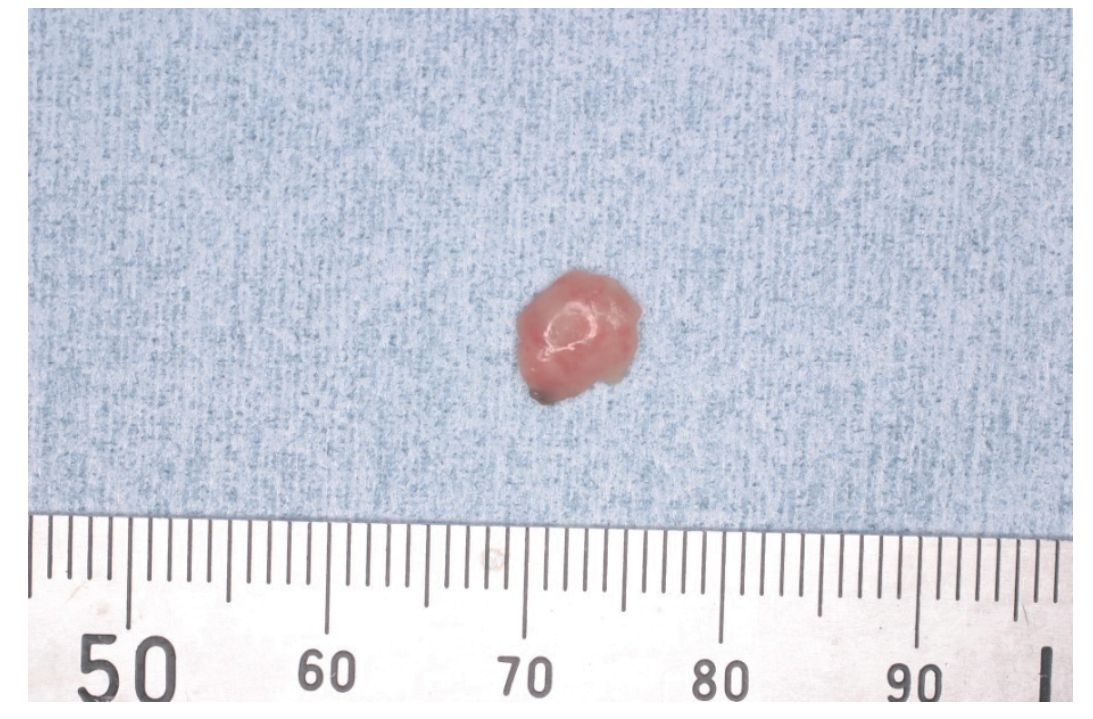

Fig.2 The mass fell out of the tongue looked lightly red granulation tissue with smooth surface. Epithelial covering lacked. 
Fig.3
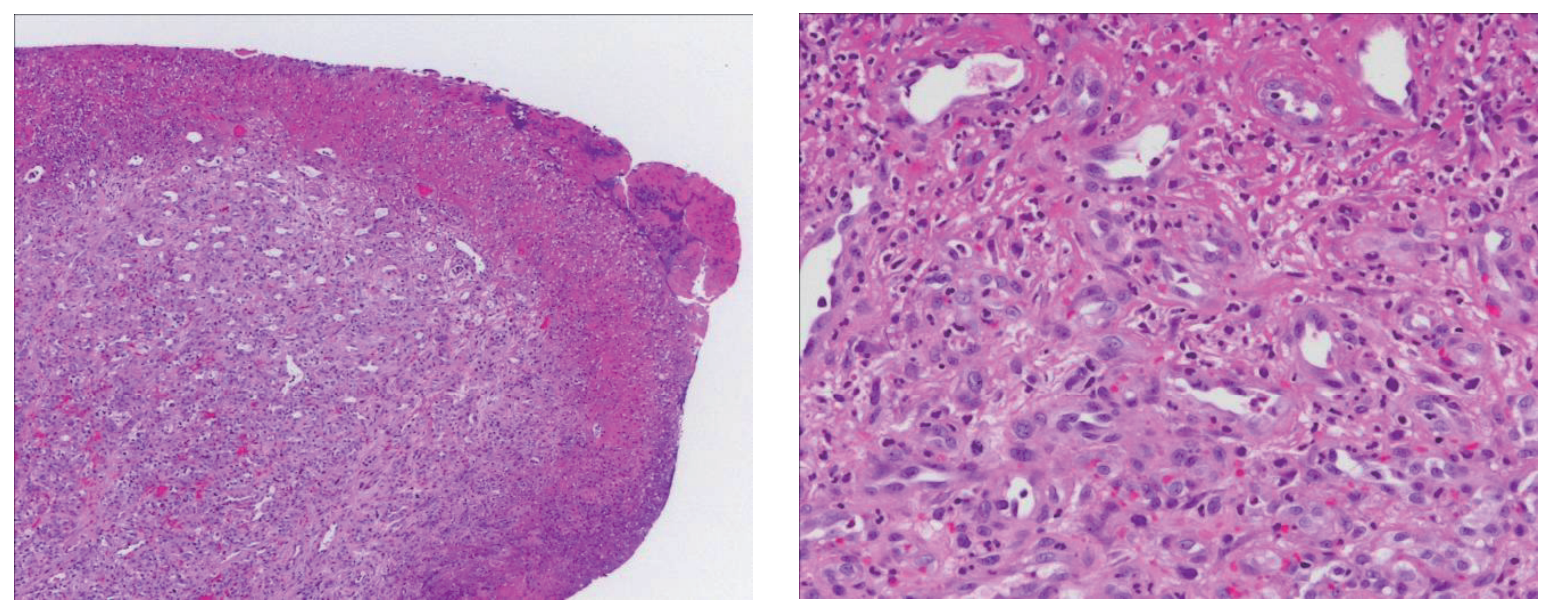

A

B

Fig.3 Histology of the mass dropped out of the tongue.

(A) Fibrin was deposited on the ulcerated surface. Many blood capillaries were noticed under the ulcer. (B) Endothelial cell proliferation with vascular formation was seen in inner portion. Neutrophils infiltrated around the dilated blood vessels. 
Fig.4

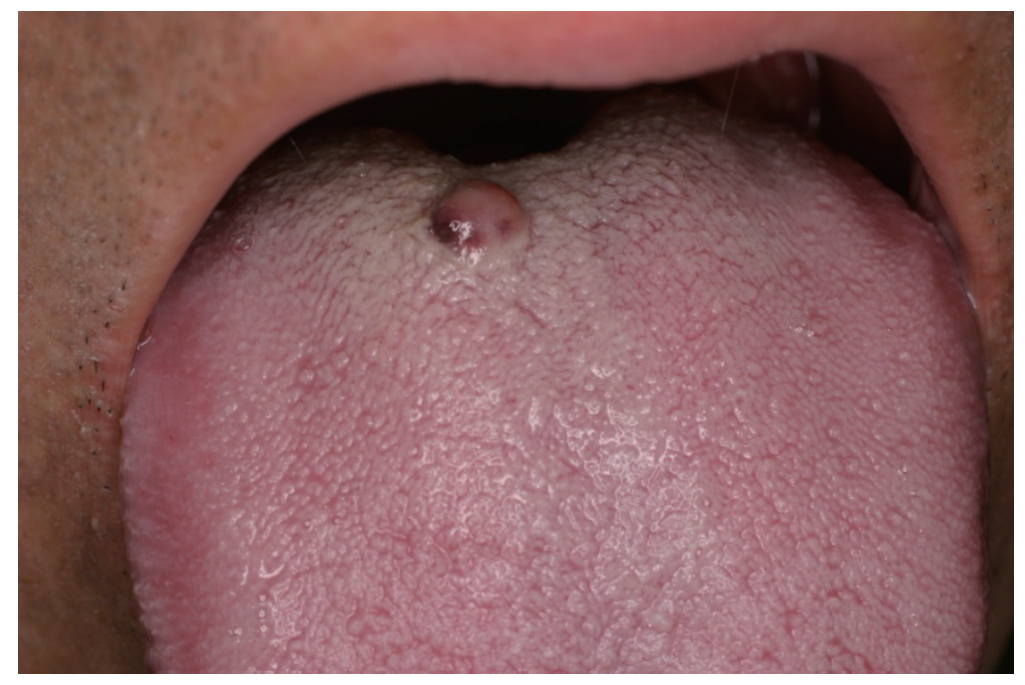

Fig.4 Clinical appearance of the lingual lesion at the time of second examination 
Fig.5

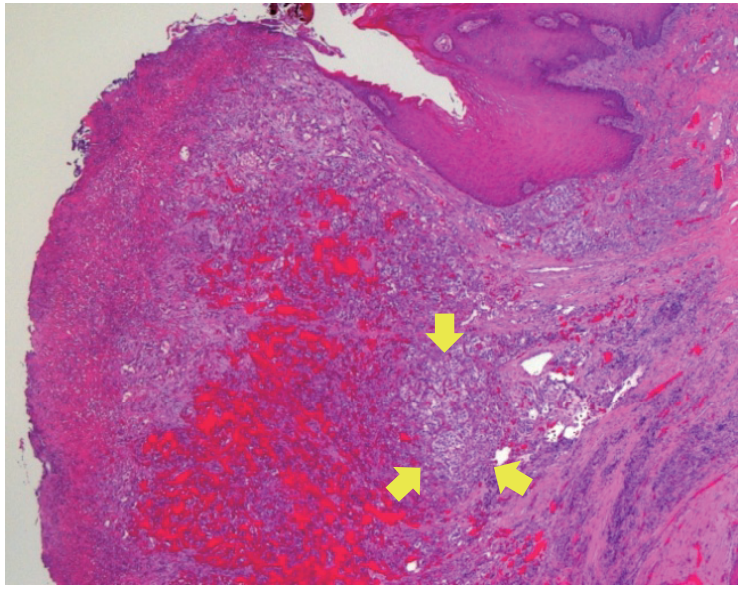

A

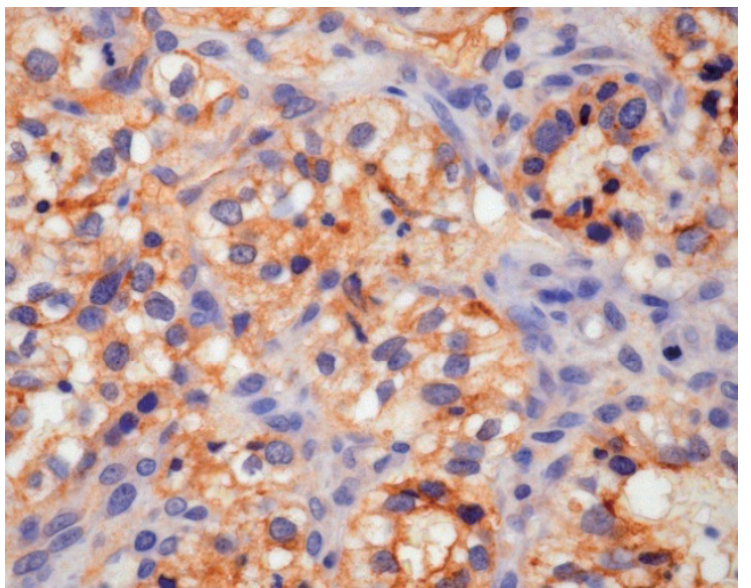

C

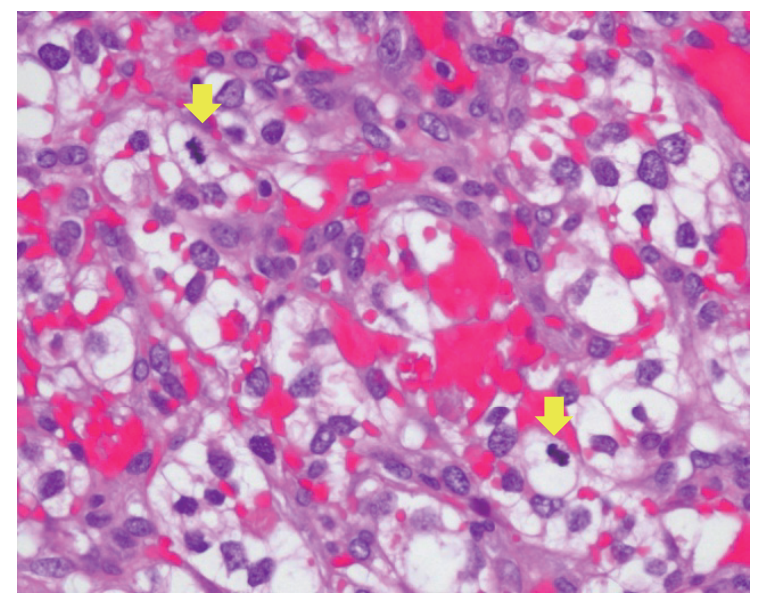

B

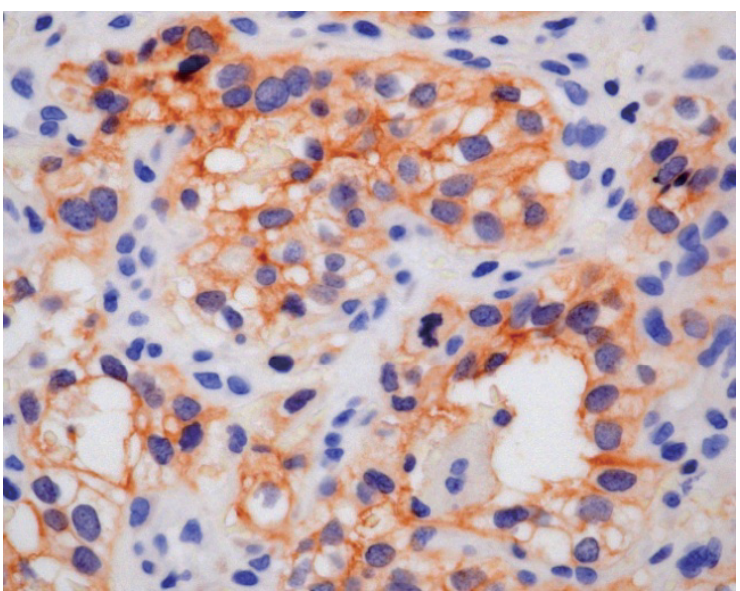

$\mathrm{D}$

Fig.5 Histology of excisional biopsy specimen.

(A) Polypoid mass had ulcerated surface deposited with fibrin. Hemorrhage and aggregation of clear cells (arrows) were seen. (B) High-power view of the aggregation of clear cells. Trabecular or ductal structures were found with erythrocytes. Mitotic figures were scattered. Immunohistochemically, the clear tumor cells were positive for EMA (C) and CD10 (D). 
Fig.6

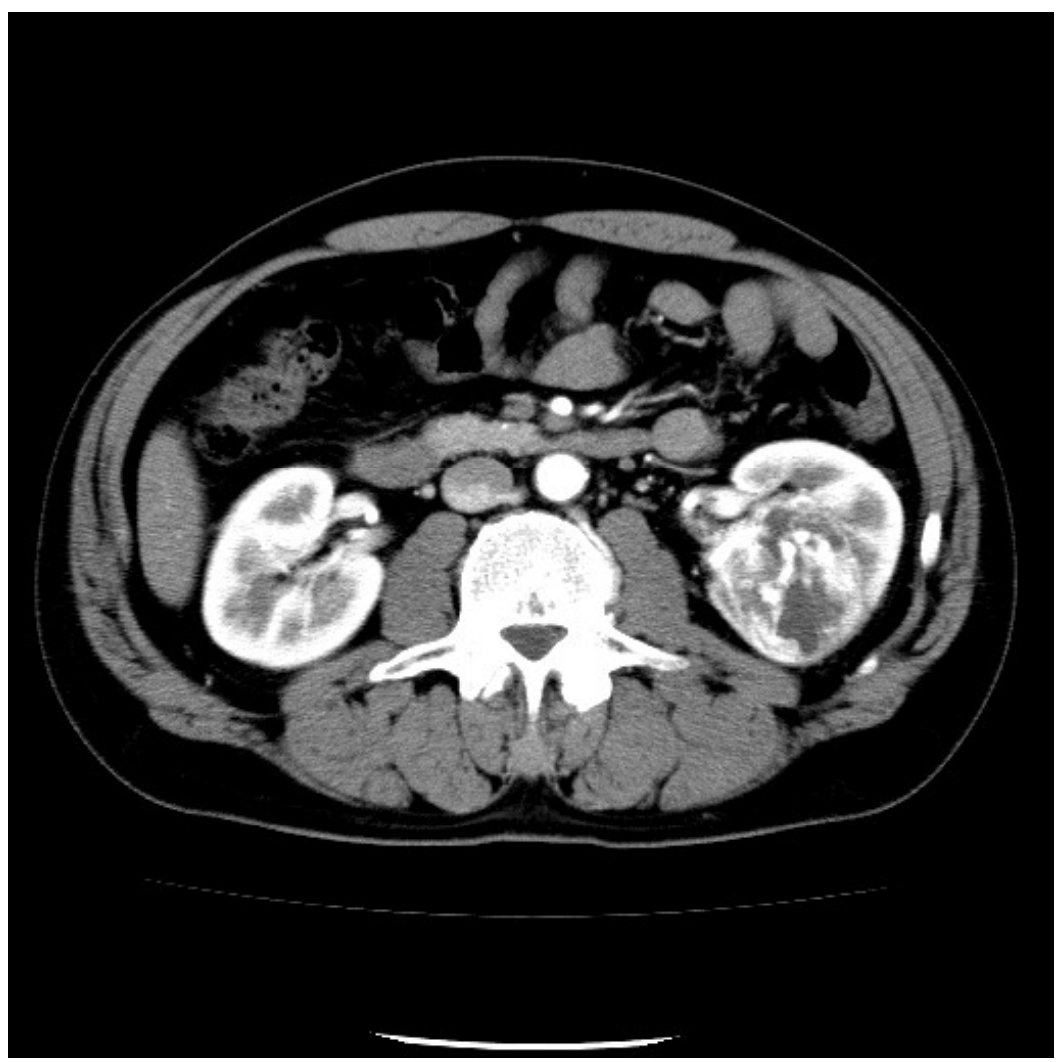

Fig.6 CT scan showing primary tumour of left kidney 
Fig.7

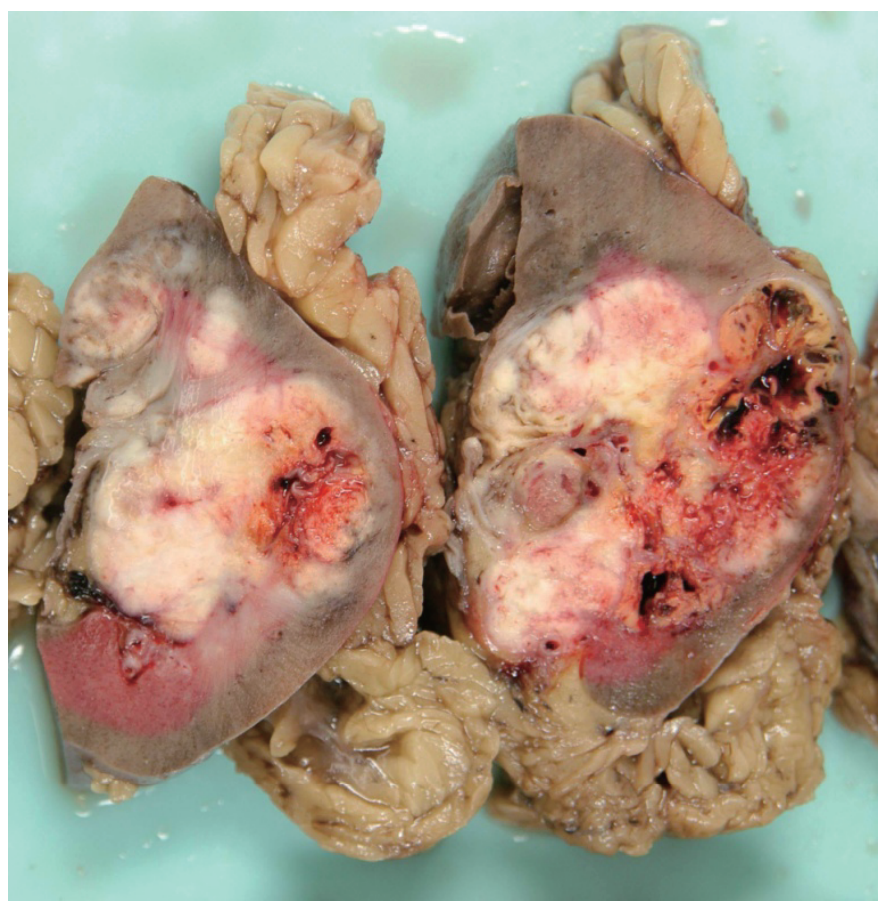

Fig.7 Cut surface of removed kidney. Some yellowish-white nodules occupied from the cortex to the hilus. Hemorrhage, necrosis and cystic change were found. 
Fig.8

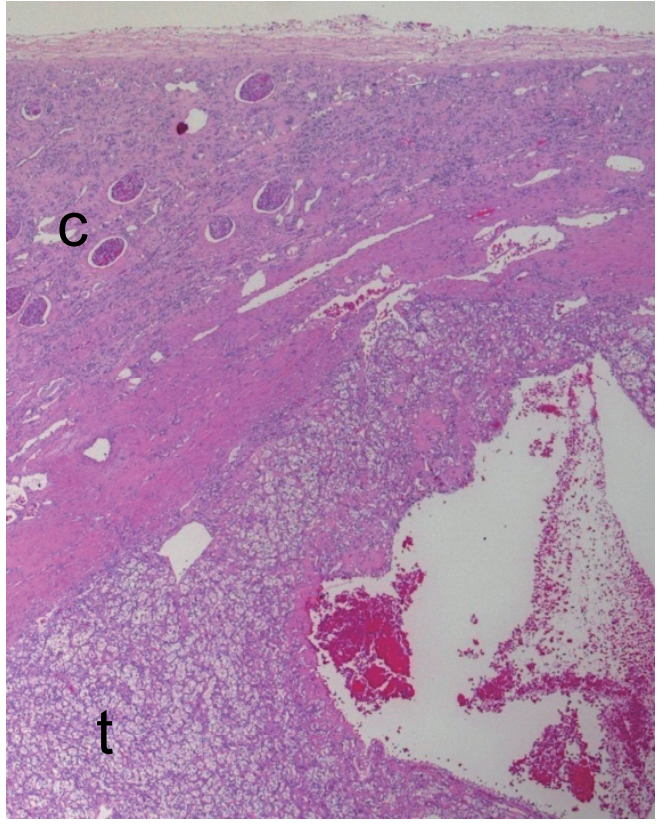

A

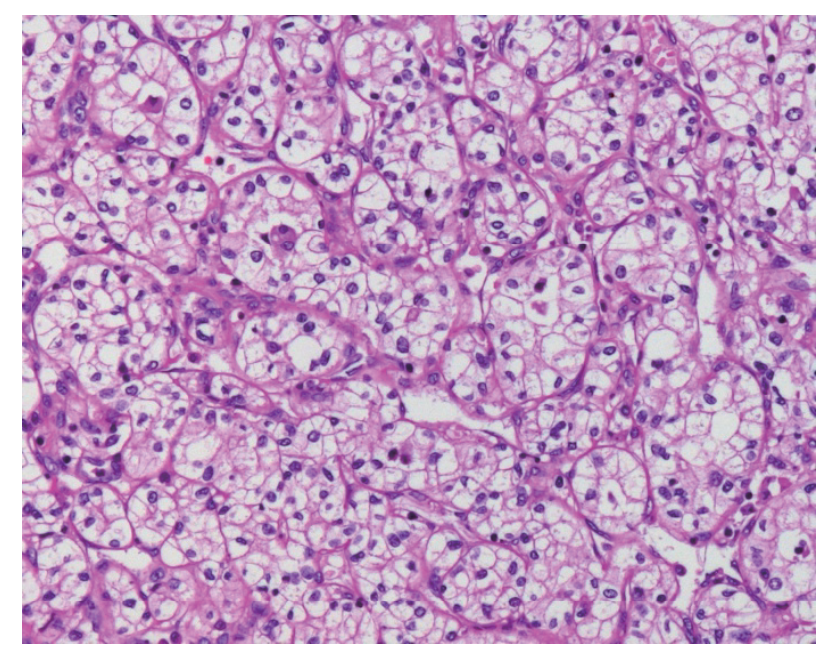

B

Fig.8 Histology of the primary renal carcinoma.

(A) The tumor was well demarcated (c: renal cortex, t: tumor nodule). The tumor show hemorrhagic degeneration. (B) Round to cuboidal tumor cells with clear cytoplasm were arranged in trabecular pattern with sinusoid-like blood vessels. 
Table.1 Previously Published Cases of Metastatic Renal cell carcinoma to the tongue

\begin{tabular}{rrrllll}
\hline & Age & Sex & \multicolumn{1}{c}{ Site } & \multicolumn{1}{c}{ Other metastases } & year & \multicolumn{1}{c}{ Author. } \\
\hline 1 & 41 & F & Surface & Lung & 1974 Satomi et al. \\
2 & 84 & M & Tip & Lung & 1979 Friedlander et al. \\
3 & 63 & M & Dorsum & Brain & 1982 Fitzgerald et al. \\
4 & 37 & M & Base & None & 1986 Kitao et al. \\
5 & 42 & M & Base & Lung & 1987 Inai et al. \\
6 & 77 & F & Surface & Lung & 1987 Matsumoto et al. \\
7 & 70 & M & Not mentioned & Not mentioned & 1987 Kapoor et al. \\
8 & 63 & M & Ventral surface & Lung, Liver & 1988 Madison et al. \\
9 & 59 & F & & Lung, Bone & 1991 Ishikawa et al. \\
10 & 58 & M & Base & Lung, Brain & 1992 Okabe et al. \\
11 & 41 & M & Base & Lung, Bone, lymph nodes & 1993 Shibayama et al. \\
12 & 59 & M & Right base & None & 1994 Ziyada et al. \\
13 & 51 & M & & Lung & 1995 Airoldi et al. \\
14 & 82 & F & Tip & Brain & 1996 Aguirre et al. \\
15 & 59 & M & & Para-aortic, lymph nodes & 1997 Konya et al. \\
16 & 50 & M & Border & Lung, Brain, Skin & 1998 Tomita et al. \\
17 & 62 & M & Lateral & Lung & 2000 Navarro et al. \\
18 & 60 & M & Base and Anterior & Lungs & 2002 Pritchyk et al. \\
19 & 62 & M & Surface & Lung & 2003 Goel et al. \\
20 & 45 & M & Tip & Nose, Lungs & 2003 Emer et al. \\
21 & 87 & F & Dorsum & Lung, Liver, thyroid, pancreas & 2004 Marioni et al. \\
22 & 66 & M & Base & Lungs & 2004 Kyan et al. \\
23 & 73 & M & Border & Lungs, Bone,Choroidea & 2005 Tachi et al. \\
24 & 49 & F & Dorsum & Lungs & 2006 Torres-Carranza et al. \\
25 & 76 & F & Base & Lungs, Liver & 2006 Cochrane et al. \\
26 & 82 & M & Border & Lungs,Brain & 2007 Tanaka et al. \\
27 & 78 & M & Lateral & Lungs, Bone & 2008 Azam, F. et al. \\
28 & 46 & F & Left base & Humerus & 2009 & Basely et al. \\
29 & 47 & M & Dorsum & Adrenal gland, Pleura, Lungs & 2010 Present case \\
\hline & & & & &
\end{tabular}


Table.2 Tongue metastasis as the initial presentation of RCC

\begin{tabular}{cccccccc}
\hline No & Age & Sex & Site & Size & $\begin{array}{c}\text { Management of } \\
\text { tongue metastasis }\end{array}$ & Year & Authors \\
\hline 1 & 70 & M & Not mentioned & Not mentioned & Not mentioned & 1987 & Kapoor et al. \\
2 & 59 & M & Base & $2 * 1 \mathrm{~cm}$ & local excision & 1994 & Ziyada et al. \\
3 & 82 & $\mathrm{~F}$ & Tip & $2 * 2 \mathrm{~cm}$ & $\begin{array}{c}\text { wide resection } \\
\text { Debulking surgery }\end{array}$ & 1996 & Aguirre et al. \\
4 & 78 & $\mathrm{M}$ & Lateral & $3 * 2 \mathrm{~cm}$ & $\begin{array}{r}\text { Dadiotherapy 60Gy } \\
\text { +Ros }\end{array}$ & Azam et al. \\
5 & 47 & $\mathrm{M}$ & Dorsul & $5 \mathrm{~mm}$ & wide resection & 2010 & Present case \\
\hline
\end{tabular}

